\title{
Outcome of pregnancy in diabetic women in northeast England and in Norway, 1994-7
}

\author{
G Hawthorne, L M Irgens, R T Lie
}

Northern Diabetic Pregnancy Survey, Regional Maternity Survey Office, Newcastle upon Tyne NE2 4AA

Gillian Hawthorne consultant physician Medical Birth Registry of Norway, Hauletend Hospital, N-5021 Bergen,

Norway

L M Irgens

professor

R T Lie

professor of medical

statistic

Correspondence to: G C Hawthorne gillian.hawthorne@ nth.northy.nhs.uk

BMJ 2000;321:730-1
In northeast England, perinatal mortality is five times higher and congenital malformation is four times higher for pregnancies in diabetic women than for those in women who do not have diabetes. ${ }^{1}$ The same is true in other regions in the United Kingdom, ${ }^{23}$ but this is not the case in Norway. ${ }^{4}$ Why is the outcome of pregnancy in diabetic women better in Norway? Does Norway use the same definitions and record the same outcome data as the United Kingdom? If the data are standardised will these differences disappear? If not, what is causing the difference in the outcome of pregnancy in diabetic women?

The methodology for data collection needs to be standardised between the two countries to determine whether differences in outcome are real before looking for explanations in the healthcare systems of the two countries. We compare the outcome of pregnancy in women with diabetes based on prospective population data collected in Norway and northeast England.

\section{Methods and results}

All data were prospectively collected in Norway and northeast England between 1 July 1994 and 30 June 1997. In Norway, all births with a gestational age of 16 completed weeks or more must be registered with the medical birth registry of Norway. Health problems such as diabetes are recorded in all women before and during pregnancy. Birth defects that are diagnosed before the child leaves hospital are recorded. Data are routinely linked with the cause of death register. In northeast England, the northern diabetic pregnancy survey collects prospective population based data on the outcome of pregnancy in diabetic women. Data on the total birth population are collected by the Regional Maternity Survey Office.

All women with pregestational diabetes who gave birth between 1 July 1994 and 30 June 1997 were included in the study. The same definitions for stillbirth and congenital anomaly were used by both centres. Stillbirths included all fetal deaths at more than 24 completed weeks of gestation. The data for Norway have been based on stillbirth $>24$ weeks, although the World Health Organization's definition of $>28$ weeks or $1000 \mathrm{~kg}$ is used routinely in Norway. Perinatal mortality comprised all stillbirths $>24$ completed weeks and all live births. Congenital anomalies were coded by using ICD-8 (international classification of diseases, 8th revision). Terminations for birth defects (to the extent reported) have been included in numerators and denominators. Perinatal deaths have been included in the denominator data. Relative risks were approximated by odds ratio; $\mathrm{P}$ values and confidence limits were obtained by using exact inference methods. Adjustment for maternal age did not alter the results. Attempts to adjust for birth order failed because too many births had information missing.

Perinatal mortality among babies born to mothers without diabetes in northeast England was 10/1000. Among babies born to mothers with diabetes it was $42.8 / 1000$, a relative risk of $4.4(95 \%$ confidence interval 2.5 to 7.7 ).

In Norway, perinatal mortality was $10.4 / 1000$ and $6.7 / 1000$ respectively for babies of mothers with diabetes and mothers without diabetes (relative risk of $1.5,0.97$ to 2.3). The relative risks in northeast England and Norway were significantly different $(\mathrm{P}=0.002)$.

The risk of birth defects was increased 2.5-fold among babies of mothers with diabetes in northeast England (1.5 to 4.0$)$. In Norway the risk was increased 0.95 -fold (0.73 to 1.2). These relative risks were significantly different $(\mathrm{P}=0.0008)$ (table).

\section{Discussion}

Pregnancy in diabetic women remains high risk in northeast England, in contrast to Norway, where outcome approaches the WHO's St Vincent target. ${ }^{5}$

Perinatal mortality and birth defects in babies born to mothers with and without diabetes, 1 July 1994-30 June 1997 in northeast England and Norway

\begin{tabular}{|c|c|c|c|c|}
\hline & No affected & No not affected & Per 1000 & Odds ratio $(95 \% \mathrm{Cl})$ \\
\hline \multicolumn{5}{|l|}{ Perinatal mortality* } \\
\hline \multicolumn{5}{|l|}{ Northeast England: } \\
\hline Maternal diabetes $(n=304)$ & 13 & 291 & 42.8 & \multirow{2}{*}{4.4 (2.5 to 7.7$)$} \\
\hline No maternal diabetes $(\mathrm{n}=101516)$ & 1014 & 100502 & 10.0 & \\
\hline \multicolumn{5}{|l|}{ Norway: } \\
\hline Maternal diabetes $(\mathrm{n}=2019)$ & 21 & 1998 & 10.4 & \multirow{2}{*}{$1.5(0.97$ to 2.3$)$} \\
\hline No maternal diabetes $(\mathrm{n}=179754)$ & 1212 & 178542 & 6.7 & \\
\hline \multicolumn{5}{|l|}{ Birth defects per $1000 \dagger$} \\
\hline \multicolumn{5}{|l|}{ Northeast England: } \\
\hline Maternal diabetes $(n=309)$ & 17 & 292 & 55.0 & \multirow{2}{*}{$2.5(1.5$ to 4.0$)$} \\
\hline No maternal diabetes $(n=101755)$ & 2472 & 99285 & 24.3 & \\
\hline \multicolumn{5}{|l|}{ Norway: } \\
\hline Maternal diabetes $(\mathrm{n}=2019)$ & 58 & 1961 & 28.7 & \multirow{2}{*}{0.95 (0.73 to 1.2$)$} \\
\hline No maternal diabetes $(n=179754)$ & 5465 & 174289 & 30.4 & \\
\hline
\end{tabular}

*The differences were significant $(P=0.002)$ for the relative risk of perinatal mortality in northeast England and Norway adjusted for maternal age

TThe differences were significant $(P=0.0008)$ for relative risks for birth defects in northeast England and Norway adjusted for maternal age. 
This is not explained by the process of data collection as care has been taken to make the data from both sources comparable. To determine the reasons for this marked difference in outcome more extensive investigation is required.

We thank Debbie Sen, Dr Judith Rankin, and Marjorie Renwick of the Regional Maternity Survey Office, Newcastle upon Tyne for their help in compiling the Northern region data and Vicki Ashton of Teesside University for statistical advice.

Contributors: GH had the original idea for the study and coordinated the data analysis. LMI supplied the data from Norway. RTL supplied the statistical expertise. The paper was written jointly by GH, LMI, and RTL.

Conflict of interest: None.
1 Hawthorne G, Robson S, Ryall EA, Sen D, Roberts SH, Ward Platt MP Prospective population based survey of outcome of pregnancy in diabetic women: results of the Northern Diabetic Pregnancy Audit, 1994. BMJ 1997;315:279-81.

2 Casson IF, Clarke CA, Howard CV, McKendrick O, Pennycook S, Pharoah $\mathrm{POD}$, et al. Outcomes of pregnancy in insulin dependent diabetic women: results of a five year cohort study. BMJ 1997;315:275-8.

3 Hadden DR, McCance D, Traub AI. Ten year outcome of diabetic pregnancy in Northern Ireland: the case for centralisation. Diabetic Med 1998(suppl 1);15:S16.

4 Hellesen HB, Vikane E, Lie RT, Irgens LM. Maternal diabetes: falling perinatal mortality but still high foetal growth. Tidsskr Nor Laegeforen 1996;116:3465-9

5 Diabetes Care and Research in Europe: the Saint Vincent Declaration WHO/IDF Europe. Diabetic Med 1990;7:360.

\title{
Decrease in effectiveness of routine surveillance of Haemophilus influenzae disease after introduction of conjugate vaccine: comparison of routine reporting with active surveillance system
}

\author{
Babatunde Olowokure, Jeremy Hawker, Iain Blair, Nick Spencer
}

In October 1992 routine immunisation with Haemophilus influenzae type $\mathrm{b}$ conjugate vaccine was introduced in the United Kingdom, and the incidence of disease was subsequently reported to have decreased 15-fold. ${ }^{1}$ The surveillance systems in place were primarily routine and were known to underestimate the burden of invasive $H$ influenzae disease. ${ }^{2}$ This study aimed to determine whether underreporting continued after introduction of the conjugate vaccine, and how this might affect the reported success of the vaccine. Results of routine surveillance were compared with active surveillance for invasive $H$ influenzae disease in the West Midlands health region of England.

\section{Subjects, methods, and results}

Invasive H influenzae disease was defined as an illness in which the organism was isolated from a sterile site in children aged $<5$ years admitted to hospital in the West Midlands from October 1990 to September 1992 (pre-vaccine) and from October 1992 to September 1994 (post-vaccine).

Data from voluntary laboratory reports to the Public Health Laboratory Service Communicable Disease Surveillance Centre (routine system) were compared with a system that combined data from the Communicable Disease Surveillance Centre, statutory notifications, laboratory records, hospital paediatricians, and the British Paediatric Surveillance Unit study of conjugate vaccine failures (active system). Hospitals and laboratories were visited to validate reports and collect demographic data. Only children aged $<5$ years who lived in the West Midlands are included in the analysis.

Of 244 West Midlands cases identified, only 200 cases had been reported to the routine surveillance system (table). Significantly fewer cases were reported to the routine surveillance system than to the active surveillance system in the post-vaccine period than in the pre-vaccine period ( $\mathrm{P}=0.0018$, table). Overall, the proportion of children aged $<2$ years identified by the routine surveillance system was significantly lower than that of children aged $>2$ years $(\mathrm{P}=0.0065$, table). Reporting by ethnic group, sex, or mortality did not differ significantly. Of seven cases reported to the British Paediatric Surveillance Unit, only three were reported to the routine surveillance system. Incidence rates based on reports to the routine surveillance system for the pre-vaccine and post-vaccine periods were 23.4 per 100000 children $<5$ years old $(95 \%$ confidence interval 19.9 to 27.2 ) and 5.1 (3.6 to 7.1) respectively. This compares with 27.1 (23.3 to 31.2) and 7.7 (5.8 to 10.0) using active surveillance data. The table shows that effectiveness of routine surveillance decreased by $23 \%$ after introduction of the vaccine, with consequent overestimation of the effectiveness of the immunisation programme.

Comparison of cases of invasive Haemophilus influenzae disease in children $<5$ years identified by active surveillance and reports to the Communicable Disease Surveillance Centre (routine system) before and after introduction of the vaccine: West Midlands Health Region 1990-4

\begin{tabular}{lccc} 
& $\begin{array}{c}\text { Routine } \\
\text { surveillance } \\
\text { system }\end{array}$ & $\begin{array}{c}\text { Active } \\
\text { surveillance } \\
\text { system }\end{array}$ & $\begin{array}{c}\text { Proportion (95\% Cl) of } \\
\text { routine: active cases }\end{array}$ \\
\hline Total number of cases: & 200 & 244 & 81.9 (76.8 to 86.4) \\
\hline Oct 1990-Sept 1992 & 164 & 190 & 86.3 (80.9 to 90.7) \\
\hline Oct 1992-Sept 1994 & 36 & 54 & 66.7 (53.4 to 78.2) \\
\hline Cases of meningitis: & 136 & 165 & 82.4 (76.0 to 87.7) \\
\hline Oct 1990-Sept 1992 & 113 & 130 & 86.9 (80.3 to 91.9) \\
\hline Oct 1992-Sept 1994 & 23 & 35 & $65.7(49.0$ to 79.9$)$ \\
\hline Cases of non-meningitic invasive disease: & 64 & 79 & $81.0(71.2$ to 88.5$)$ \\
\hline Oct 1990-Sept 1992 & 51 & 60 & 85.0 (74.3 to 92.4) \\
\hline Oct 1992-Sept 1994 & 13 & 19 & 68.4 (45.5 to 86.1) \\
\hline Age group (months): & 139 & 179 & 77.7 (71.1 to 83.3) \\
\hline 0-23 & 61 & 65 & 93.8 (85.8 to 98.0) \\
\hline 24-59 & & &
\end{tabular}

